\title{
Clinical and neurophysiological features of the hereditary neuropathy with liability to pressure palsy due to the 17p11.2 deletion
}

Aspectos clínicos e neurofisiológicos de pacientes com a neuropatia hereditária com a susceptibilidade à pressão associada à deleção 17 p11.2

Aline Pinheiro Martins de Oliveira, Raquel Campos Pereira, Patrícia Toscano Onofre, Vanessa Daccach

Marques, Gilberto Brown de Andrade, Amilton Antunes Barreira, Wilson Marques Junior

\begin{abstract}
The hereditary neuropathy with liability to pressure palsies (HNPP) is an autossomal dominant disorder manifesting recurrent mononeuropathies. Objective: Evaluate its clinical and nerve conduction studies (NCS) characteristics, searching for diagnostic particularities. Method: We reviewed the neurological manifestations of 39 and the NCS of 33 patients. Results: Family history was absent in 16/39 (41\%). The onset complaints were weakness in 24, pain in 6, sensory deficit in 5 and paresthesias in 4. Pain was seen in 3 other patients. The following neuropathy patterns were found: multiple mononeuropathy (26), mononeuropathy (7), chronic sensorimotor polyneuropathy (4), chronic sensory polyneuropathy (1) and unilateral brachial plexopathy (1). NCS showed a sensorimotor neuropathy with focal conduction slowing in 31, two had mononeuropathy and another brachial plexopathy. Conclusion: HNPP presentation is variable and may include pain. The most frequent pattern is of an asymmetrical sensory and motor neuropathy with focal slowing at specific topographies on NCS.
\end{abstract}

Keywords: hereditary neuropathy with liability to pressure palsies, peripheral neuropathy, nerve conduction study, pain.

\section{RESUMO}

A neuropatia hereditária com susceptibilidade à pressão (HNPP) é uma doença autossômica dominante que manifesta mononeuropatias recorrentes. Objetivo: Avaliar as características clínicas e os estudos da condução nervosa (ECN) procurando particularidades diagnósticas. Método: Revisamos as características clínicas de 39 e os ECN de 33 pacientes. Resultados: História familiar ausente em 16/39 (41\%). As manifestações iniciais foram: fraqueza em 24, dor em 6, déficit sensitivo em 5 e parestesias em 4. Dor foi referida por outros 3 pacientes. Os seguintes padrões de neuropatia foram observados: mononeuropatia múltipla (26), mononeuropatia (6), polineuropatia sensitivo-motora (4), polineuropatia sensitiva (1) e plexopatia braquial unilateral (1). Os ECN mostraram uma neuropatia sensitivo-motora com redução focal da velocidade de condução em 31, dois tinham mononeuropatia e outro plexopatia braquial. Conclusão: A apresentação da HNPP é variável e pode incluir dor. O padrão mais frequente é o de uma neuropatia sensitivo-motora assimétrica com alentecimentos focais da condução em topografias específicas nos ECN.

Palavras-chave: neuropatia hereditária com susceptibilidade à pressão, neuropatia periférica, estudos da condução nervosa, dor.

The hereditary neuropathy with liability to pressure palsies (HNPP) is an autossomal dominant disorder characterized by recurrent sensory and motor mononeuropathies that tend to occur at entrapment sites, although occasional patients present a generalized neuropathy ${ }^{1,2,3}$. Most cases of HNPP are associated to PMP22 gene deletion ${ }^{4}$. Point mutations in the same gene occasionally cause HNPP and at least 26 small mutations have been found ${ }^{5}$. The same region is duplicated in
Charcot-Marie-Tooth disease type 1A (CMT1A $)^{6}$, the most frequent inherited neuropathy.

In contrast to CMT1A, in which nerve conduction slowing is uniform along the entire nerve length ${ }^{5,7,8,}, \mathrm{HNPP}$ is characterized by multifocal or segmental conduction abnormalities ${ }^{1,10,11,12,13}$, being necessary a correct distinction from other acquired and treatable neuropathies. Diagnosis of HNPP is also important for correct prognostic evaluation and genetic counseling.

Universidade de São Paulo, Faculdade de Medicina de Ribeirão Preto, Departamento de Neurociências e Ciências do Comportamento, Ribeirao Preto SP, Brazil. Correspondence: Wilson Marques Jr; Departamento de Neurociências e Ciências do Comportamento, Faculdade de Medicina de Ribeirão Preto / USP; Avenida Bandeirantes, 3900; Campus da USP; 14049-900 Ribeirão Preto SP, Brasil; E-mail: wmjunior@fmrp.usp.br Conflict of interest: There is no conflict of interest to declare.

Support: We wish to thank all staff of the Clinical Neurophysiology Unit and of the Neurogenetic Laboratory for their valuable support. Received 22 April 2015; Received in final form 12 September 2015; Accepted 01 October 2015. 
Sporadic cases are sometimes found $d^{3,14}$. They may result from de novo mutations ${ }^{3}$, incomplete family history, adoption, false paternity and no recognition of minor manifestations as signs of neuropathy.

The classic phenotype is the occurrence of acute or subacute painless mononeuropathy after minor trauma ${ }^{2,14}$. Patients frequently complaint of paresthesias after a short period of time in positions that result in nerve compression. The prognosis is relatively benign and most mononeuropathies resolve spontaneously. Severe injuries are avoided if the patient learns to protect his nerves ${ }^{15}$.

Atypical presentations as chronic sensory-motor polyneuropathies have been described in young ${ }^{3}$, adults ${ }^{1,2}$ and seniors ${ }^{11}$. Around $30 \%$ of the patients have chronic symptoms such as cramps, paresthesias and myalgia induced by exercise ${ }^{11}$. Pain was considered rare ${ }^{2,16}$, but recent studies described pain in patients with upper limbs mononeuropathies ${ }^{17,18}$ and occasionally neuropathic pain may be found ${ }^{17}$. Some patients present musculoskeletal pain that meet the fibromyalgia criteria, potentially delaying diagnosis ${ }^{19}$.

There is no consensus for the neurophysiology of HNPP. Verhagen et al. ${ }^{20}$ proposed that the most discriminating findings (99\% accuracy) were slowing of conduction velocity (CV) of the fibular nerve from the fibula head to the ankle, slowing of the ulnar nerve conduction at the elbow and prolongation of the distal motor latency (DML) of at least one of the fibular nerves. Mouton et al. ${ }^{2}$ and Gouider et al. ${ }^{15}$ found that after 15 years of age all patients present prolonged DML and reduction of the wrist sensory $\mathrm{CV}$ of the median nerve and prolongation of the DML or reduction of the CV of at least one of the fibular nerves. Cruz-Martinez et al..$^{21}$ found that the DML of the median nerve, the sensory CV of the median nerve at the wirst and the sensory $\mathrm{CV}$ of the sural nerves were abnormal in all affected individuals ${ }^{21}$.

Guidelines to the diagnosis of HNPP were proposed by Dubourg et al. ${ }^{16}$ : a) bilateral increase in DML of the median nerves associated with reduced CV in median sensory nerve at the palm-wrist segment; b) at least one of the fibular nerves should have increased DML or reduced CV; c) CV of the ulnar nerve at the elbow segment is frequently reduced; d) CV in the lower limb nerves may be moderately reduced and e) SNAP amplitudes may be reduced, mostly in the upper limbs. Infante et al. ${ }^{3}$ proposed that the neurophysiological evaluation of patients suspected of having HNPP should include the motor conduction in, at least, two anatomical sites of nerve compression, particularly the ulnar nerve at the elbow and the study of the sural nerve ${ }^{3}$.

Li et al..$^{12}$ showed that there is a unique electrophysiological pattern in HNPP, characterized by severe distal slowing in some nerves, multifocal conduction slowing at the sites of entrapment and mildly reduced CV in other segments. Distal sensory conduction velocities are usually diffusely abnormal. These findings were consistent with those of some previous reports ${ }^{1,2,3,10,11,22}$ The distal slowing was more frequent in median and fibular nerves, more liable to pressure palsies and repetitive trauma.
Interestingly, the distal latencies to more proximal muscles did not present slowing, a strong argument against HNPP being a distal myelinopathy as suggested by others ${ }^{1,22}$.

Luigetti et al. ${ }^{23}$ proposed that HNPP should be suspected in patients with a demyelinating neuropathy associated to carpal tunnel syndrome, plus another motor conduction abnormality (CV of the ulnar nerve at the elbow, DML of the ulnar nerve, $\mathrm{CV}$ of the fibular nerve) plus a sensory nerve conduction abnormality in a nerve not prone to compression (sural or radial nerves). Following this criteria over a 20-year period, they genetically confirmed the diagnosis of HNPP in more than $70 \%$ of the suspected cases.

In order to shed more light about the clinical and the electrophysiologic patterns of HNPP we analyzed a group of our patients with the $17 \mathrm{p} 11.2$ deletion.

\section{METHOD}

We have included patients with HNPP carrying the 17p11.2-12 deletion regularly followed at our institution. Those with other causes of neuropathy, including alcoholism, malnutrition, vitamin B12 deficiency and systemic diseases, as diabetes and other endocrinopathies, were not considered. Their records were evaluated retrospectively. Ethics approval was obtained from the Ethics Committee at the HCFMRP-USP.

The patients were evaluated with special emphasis on the neuromuscular system. Electromyography (EMG) evaluation was performed in 33 patients, using surface stimulation and recording for the motor conduction studies and surface stimulation and needle recording electrodes for sensory conduction studies. Compound muscle action potentials (CMAP) were recorded from median, ulnar, fibular and posterior tibial nerves. The following characteristics were studied: amplitude, motor conduction velocity (MCV), distal motor latency (DML) and minimal F-wave latency. The following segments were studied: a) median nerve: wrist to antecubital fossa and antecubital fossa to axilla; b) ulnar nerve: wrist to below elbow, below to above elbow, above elbow to axilla; c) fibular nerve: ankle to below fibular head and below to above fibular head; and d) posterior tibial nerve: ankle to popliteal fossa.

Conduction block (CB) was defined as a $50 \%$ or greater decrease in negative peak amplitude and area of the proximal CMAP. Focal slowing at a compression site was considered present when a decrement $\geq 10 \mathrm{~m} / \mathrm{s}$ was identified. Compound sensory nerve action potentials (SNAP) were recorded orthodromically from median (index finger-wrist and palm-wrist) and ulnar (fifth finger-wrist and palm-wrist) nerves and antidromically from radial (forearm-base of the thumb), sural (midcalf-lateral malleolus) and superficial fibular (leg-ankle) nerves. The following parameters were analyzed: SNAP amplitude, sensory CV (SNCV), duration and morphology.

The data obtained were compared to the normative values of the Clinical Neurophysiology Laboratory of our 
institution. Undetected potentials were generally classified as abnormal. Statistical analysis was carried on with the SPSS Statistic version 17.0 software (SPSS Inc.). Means and percents were compared using the Student's t-test or Q-square test, and differences were considered significant at $\mathrm{p} \leq 0.05$.

\section{RESULTS}

Thirty-nine patients (21 men and 18 women), including a mother and daughter, fulfilled our inclusion criteria. Family history was absent in 16/39 (41\%). The mean age of disease onset was 24 years ( 5 to 76 years), while the mean age of the first evaluation was 32 years ( 6 to 77 years). The time of onset to evaluation was on average 8.2 years.

The first spontaneous complaints were localized muscular weakness in 24 patients $(61 \%)$, pain in 6 patients $(15 \%)$, sensory loss in 5 (13\%) and paresthesias in 4 (10\%) (Table 1). At least one episode of acute paralysis of a specific nerve was reported by 18 patients (46\%). 28 episodes of paralysis were reported, 19 in common fibular nerve, 6 in radial and ulnar nerves, respectively, and 2 in the axillary nerve. Position related sensory symptoms were reported by 12 patients (31\%) and a history of compression or precipitant factors preceding the paralysis in 19 patients (48\%), including playing volleyball or soccer, climbing stairs, driving vehicles, prolonged time crouched, physical effort, waking up, horse fall.

Painless symptoms were reported by 30 patients $(77 \%)$. In addition to the 6 patients that complained of pain as the initial symptom, other 3 patients reported pain at some point

Table 1. Clinical findings in 39 hereditary neuropathy with liability to pressure palsies patients with the PMP22 deletion.

\begin{tabular}{lc}
\hline Feature & \\
\hline Number of patients & $39(21 \mathrm{M} / 18 \mathrm{~F})$ \\
Age at examination mean (range) & $32(6-77)$ \\
Age at onset mean (range) & $24(5-76)$ \\
Presenting manifestations & \\
Muscle weakness & $24(61 \%)$ \\
Pain & $6(15 \%)$ \\
Sensory deficit & $5(13 \%)$ \\
Paresthesias & $4(11 \%)$ \\
Clinical features & \\
Negative family history & $16(41 \%)$ \\
History of compression & $19(48 \%)$ \\
Acute nerve palsies & $18(46 \%)$ \\
Positional sensory symptoms & $12(31 \%)$ \\
Pain & $9(23 \%)$ \\
Painless manifestations & $30(77 \%)$ \\
Pes cavus & $5(13 \%)$ \\
Generalized areflexia & $1(2 \%)$ \\
Absent ankle jerks & $8(20 \%)$ \\
Distal atrophy & $8(20 \%)$ \\
Nerve thickening & $4(10 \%)$ \\
\hline F: female; M: male. &
\end{tabular}

of their disease, triggered by physical effort ( 2 patients) and without a precipitating factor (1 patient). Of the 6 patients that reported pain as initial symptom, 3 presented a slowly progressive painful neuropathy predominantly affecting the lower limbs in the set of a chronic sensorimotor polyneuropathy on the neurological examination and 3 manifested pain in the set of a multiple mononeuropathy (1 patient with slowly progressive pain in the territory of ulnar nerve; 1 patient with slowly progressive pain in the left lower limb; 1 patient with pain in the lower limbs triggered by the maintenance of a position for a long period of time). Pain was referred by both, adults ( 7 patients) and teens (14 and 16 years old).

Pes cavus was present in 5 patients (13\%), ankle jerks were absent in $8(20 \%)$ and distal atrophy was seen in 8 (20\%). Two of the patients with atrophy had a sensorimotor polyneuropathy. In the remaining patients with muscle atrophy there was a nerve-selective distribution, most of times involving ulnar and/or median and/or fibular nerves. Nerve thickening was rare (4 patients-10\%).

None of our patients had peripheral facial nerve palsy. One patient presented a transient involvement of the trigeminal nerve and other one an episodic involvement of the eyelid branch of the oculomotor nerve.

On neurological evaluation, 26 patients (66.7\%) had a multiple mononeuropathy pattern, 7 (17.9\%) presented an isolated mononeuropathy, $4(10.2 \%)$ had a chronic sensorimotor polyneuropathy, 1 (2.6\%) developed a predominant sensory polyneuropathy and $1(2.6 \%)$ patient developed a unilateral brachial plexopathy.

The most common clinical course was intermittent, comprising a succession of acute attacks with complete or partial recovery (31 patients - 79.5\%). These patients had recurrent mononeuropathies, often from different nerves. Progressive evolution, with no obvious fluctuations, was observed in 8 patients $(20.5 \%)$, whose neuropathy pattern included multiple mononeuropathy, chronic sensorimotor polyneuropathy or purely sensory polyneuropathy on neurologic examination (Table 2 ).

Table 2. Clinical and electrophysiological patterns.

\begin{tabular}{lc}
\hline Clinical pattern & $\mathrm{N}(\%)$ \\
\hline Multiple mononeuropathy & $26(66.7)$ \\
Isolated mononeuropathy & $7(17.9)$ \\
Sensorimotor polyneuropathy & $4(10.2)$ \\
Sensory polyneuropathy & $1(2.6)$ \\
Unilateral brachial plexopathy & $1(2.6)$ \\
Total & $39(100)$ \\
\hline Electrophysiological pattern & $\mathrm{N}(\%)$ \\
\hline ASMNFS & $30(91.0)$ \\
Single mononeuropathy & $2(6.0)$ \\
Brachial plexus + ASMNFS & $1(3.0)$ \\
Total & $33(100)$ \\
\hline
\end{tabular}

N: number of patients; ASMNFS: asymmetric sensorimotor neuropathy with focal slowing. 
Nerve conduction studies were performed on 253 motor and 237 sensory nerves. Six patients underwent EMG examination in another hospital. They have not been included in this study. Despite the clinical presentation, nerve conduction studies showed a pattern of sensory and motor neuropathy with focal conduction slowing in 31 patients, including a patient with unilateral brachial plexopathy and focal conduction slowing (Table 2). Two patients had isolated mononeuropathy (a 13-year-old boy with radial neuropathy with persistent $\mathrm{CB}$ at the arm segment and one 6 years-old boy with deep fibular neuropathy).

The most affected nerves in our patients were: motor ulnar nerve (CV slowing at the elbow segment in $98.2 \%$ of the nerves), sensory ulnar nerve (CV slowing at the finger-wrist segment in $89.6 \%$ ), deep fibular nerve (at least one parameter of NCS abnormal in $83.0 \%$ of the nerves, mainly DML or F wave latency or $\mathrm{CV}$ ), sensory median nerve (CV slowing at the finger-wrist segment in $82.8 \%$ and at the palm-wrist segment in 100\%); motor median nerve (DML prolonged out of proportion to the reduction in forearm CV in $80 \%$ of the nerves), sural nerve (CV slowing in 61,7\%) and superficial radial nerve (CV reduction in 52.9\%). (Table 3).

The DML of the median nerve was more frequently prolonged than the DML of the ulnar nerve $(\mathrm{p}=0.03)$, fibular nerve $(p=0.03)$ and tibial nerve $(p<0.001)$. DML of the ulnar and fibular nerves were significantly more frequently prolonged than those of the tibial nerve $(p=0.002)$.

Temporal dispersion was observed in SNAP of median (4 times), ulnar (once) and sural nerves (once), and in CMAP of the median and ulnar nerves (once), tibial posterior and fibular nerves (4 times) inside and outside entrapment sites. $\mathrm{CB}$ of the ulnar nerve at the elbow segment was observed 7 times, once in the fibular nerve at the fibula neck and once at the leg segment and once in the radial motor nerve at spiral groove. This last patient had a persistent $\mathrm{CB}$ at this site.

\section{DISCUSSION}

The characteristics of the population with HNPP we studied seem to be similar to other studied populations ${ }^{2,11,14,15,23}$. In most patients, disease onset occurred in the first three decades of life, although the extremes were quite large, ranging from 5 to 76 years old in our patients. Additionally, the proportion between males and females approach to 1 , as was seen in a population of Brazilian patients with CMT1A that we have studied previously ${ }^{9}$. Some authors however found a male predominance (male/female $=4: 3$ ) and a significantly earlier onset in men².

Family history was positive in only 23 cases (59\%). In previous studies the percentage of sporadic cases were variable $e^{3,14}$. This finding probably reflects the wide range of the clinical manifestations, that may be very mild or even absent ${ }^{3,10,15}$ and has important clinical implications as family history very frequently is not a clue to the final diagnosis.
In 24 of the 39 patients $(61.5 \%)$, the first clinical manifestation was painless muscle weakness and at least one episode of acute nerve paralysis was reported by 18 patients. This is the classic phenotype: a painless acute or subacute mononeuropathy ${ }^{2,14}$. Among the 18 patients with acute paralysis, 12 reported some precipitating factor, what highlights the importance of environmental factors for development of the clinical manifestations. Six patients reported pain as the initial manifestation. In only one patient pain was associated to an episode of acute nerve paralysis. In the remaining 5 patients pain heralded a chronic neuropathy. Another 5 patients reported numbness and another 4 mentioned paresthesias as the initial symptoms.

Apart from the 6 patients who reported pain as the initial symptom, other 3 patients began the clinical picture with subacute or chronic muscle weakness but reported pain at some point of their evolution. The pain manifested in these cases was neuropathic, either focal associated to ulnar neuropathy, or affecting the lower limbs without a recognized precipitating factor.

Pain is rarely reported in $\mathrm{HNPP}^{2,16}$ and is considered a very uncommon in the acute episodes of nerve paralysis ${ }^{2}$, but may be the initial manifestation of the disease ${ }^{17}$ or a chronic component of this neuropathy ${ }^{18,19}$. Interestingly, it has been recently described a HNPP family due to a point mutation, whose main manifestations were pain and paresthesias, without recurrent palsies ${ }^{18}$. Ours observations corroborates the importance of considering HNPP in patients presenting pain, even in younger ages, as has happened in our population.

Cranial nerve involvement was rare in our population. We have seen a patient with paresthesias in the territory of the trigeminal nerve and another with unilateral transient paralysis of the eyelid branch of the oculomotor nerve. It seems that this is the pattern in most studies ${ }^{2,20,21,24}$. Interestingly, we have previously described a HNPP patient that developed dysphagia $^{25}$. Other rare manifestations in our patients were pes cavus and nerve thickening, as seems to be the case in most studies ${ }^{3,15}$. Clinically, most patients of our patients presented a pattern of multiple mononeuropathy or mononeuropathy as seems to occur in most series ${ }^{1,2,3,13,14}$. However, 4 patients presented a chronic sensorimotor polyneuropathy and one patient had a pure sensory polyneuropathy, both patterns are very rare in $\mathrm{HNPP}^{3,11,23}$.

In our study, one patient had unilateral clinical and neurophysiological impairment of the upper trunk of the brachial plexus. This is a very uncommonly referred presentation that is more frequent in women ${ }^{2}$ and that should be differentiated from acute brachial neuritis ${ }^{26}$ and other plexopathies that are usually painful ${ }^{27}$.

On nerve conduction studies, most of our patients (94.0\%) presented an EMG pattern of an asymmetric sensorimotor neuropathy with focal slowing of nerve conduction, suggesting a mononeuritis multiplex pattern. Even the patient that 


\begin{tabular}{|c|c|c|c|c|c|}
\hline Nerve conduction study & Normative value & $N(N D)$ & Mean \pm SD & Range & Abnormal (\%) \\
\hline \multicolumn{6}{|l|}{ Motor conduction } \\
\hline \multicolumn{6}{|l|}{$\mathrm{DML}(\mathrm{ms})$} \\
\hline Median & $\leq 4.0$ & $57(0)$ & $5.4 \pm 2.0$ & $3.2-12.0$ & 80.7 \\
\hline Ulnar & $\leq 3.1$ & $59(0)$ & $3.5 \pm 0.9$ & $2.4-6.9$ & 57.6 \\
\hline Peroneal & $\leq 5.0$ & $59(0)$ & $5.7 \pm 1.5$ & $2.7-8.6$ & 57.6 \\
\hline Tibial & $\leq 5.5$ & $53(0)$ & $5.3 \pm 1.9$ & $3.4-12.2$ & 30.2 \\
\hline \multicolumn{6}{|l|}{$\mathrm{CMAP}(\mathrm{mV})$} \\
\hline Median & $\geq 3.8$ & $57(0)$ & $8.2 \pm 3.5$ & $0.3-21.2$ & 8.8 \\
\hline Ulnar & $\geq 3.8$ & $59(0)$ & $8.9 \pm 2.3$ & $4.2-16.0$ & 0.0 \\
\hline Peroneal & $\geq 2.8$ & $59(0)$ & $4.7 \pm 2.7$ & $0.1-11.2$ & 30.5 \\
\hline Tibial & $\geq 3.6$ & $53(0)$ & $8.5 \pm 3.5$ & $0.4-16.0$ & 3.8 \\
\hline \multicolumn{6}{|l|}{$\operatorname{MNCV}(\mathrm{m} / \mathrm{s})$} \\
\hline Median & $\geq 50.0$ & $56(0)$ & $50.0 \pm 6.0$ & $34.6-62.2$ & 33.9 \\
\hline Ulnar (wrist-BE) & $\geq 50.0$ & $58(0)$ & $52.5 \pm 6.2$ & $43.4-70.0$ & 35.5 \\
\hline Ulnar (BE-AE) & $\geq 50.0$ & $57(0)$ & $32.8 \pm 9.4$ & $11.5-51.9$ & 98.2 \\
\hline Peroneal (ankle-BFH) & $\geq 40.0$ & $58(0)$ & $38.8 \pm 6.7$ & $21.3-61.9$ & 55.1 \\
\hline Peroneal (BFH-AFH) & $\geq 40.0$ & $52(0)$ & $38.8 \pm 8.3$ & $22.4-64.3$ & 44.2 \\
\hline Tibial & $\geq 40.0$ & $53(0)$ & $41.7 \pm 7.4$ & $28.1-67.8$ & 35.8 \\
\hline \multicolumn{6}{|l|}{ F latency (ms) } \\
\hline Median & $\leq 32.0$ & $52(0)$ & $30.5 \pm 5.1$ & $20.6-41.8$ & 34.6 \\
\hline Ulnar & $\leq 33.0$ & $50(2)$ & $32.0 \pm 2.8$ & $22.9-45.9$ & 38.5 \\
\hline Peroneal & $\leq 56.0$ & $47(5)$ & $56.1 \pm 7.9$ & $41.2-71.1$ & 61.5 \\
\hline Tibial & $\leq 58.0$ & $47(2)$ & $55.2 \pm 5.6$ & $43.0-64.1$ & 34.7 \\
\hline \multicolumn{6}{|l|}{ Sensory conduction } \\
\hline \multicolumn{6}{|l|}{$\mathrm{SNCV}(\mathrm{m} / \mathrm{s})$} \\
\hline Median & $\geq 50.0$ & $58(0)$ & $38.9 \pm 9.7$ & $16.3-53.6$ & 82.8 \\
\hline Median P-W & $\geq 50.0$ & $33(0)$ & $34.1 \pm 9.6$ & $11.4-49.7$ & 100.0 \\
\hline Ulnar & $\geq 50.0$ & $57(1)$ & $39.3 \pm 8.9$ & $20.8-53.5$ & 89.6 \\
\hline Ulnar P-W & $\geq 50.0$ & $28(1)$ & $36.9 \pm 6.0$ & $23.4-56.3$ & 89.3 \\
\hline Radial & $\geq 50.0$ & $34(0)$ & $46.3 \pm 6.9$ & $36.0-70.0$ & 52.9 \\
\hline Sural & $\geq 40.0$ & $55(5)$ & $38.4 \pm 5.1$ & $28.1-57.5$ & 61.7 \\
\hline Superficial peroneal & $\geq 40.0$ & $35(4)$ & $40.4 \pm 5.3$ & $27.6-56.1$ & 43.6 \\
\hline \multicolumn{6}{|l|}{$\operatorname{SNAP}(\mu \mathrm{V})$} \\
\hline Median & $\geq 9.0$ & $58(0)$ & $12.1 \pm 13.7$ & $0.6-58.0$ & 56.9 \\
\hline Ulnar & $\geq 9.0$ & $57(1)$ & $9.1 \pm 7.7$ & $1.0-50.0$ & 58.6 \\
\hline Radial & $\geq 15.0$ & $34(0)$ & $24.5 \pm 12.7$ & $8.9-51.8$ & 23.5 \\
\hline Sural & $\geq 5.6$ & $55(5)$ & $13.5 \pm 7.4$ & $2.3-42.0$ & 21.7 \\
\hline Superficial peroneal & $\geq 5.0$ & $35(4)$ & $11.6 \pm 7.3$ & $2.4-26.5$ & 33.3 \\
\hline
\end{tabular}

DML: distal motor latency; CMAP: compound muscle action potential; MNCV: motor nerve conduction velocity; F latency: minimal latency of F wave; SNCV: sensory nerve conduction velocity; SNAP: sensory nerve action potential; N: number of recorded nerves; ND: number of not detected nerves; SD: standard deviation; BE: below elbow; AE: above elbow; BFH: below fibular head; AFH: above fibular head; PW: palm wrist segment.

clinically had a plexopathy and 5 of our patients with mononeuropathy presented this pattern on neurophysiology, that seems to be the rule in the literature ${ }^{1,2,3,12,13}$. Very occasionally, NCS shows only a mononeuropathy ${ }^{2,21,23}$. The patient that showed clinically a sensory polyneuropathy also presented in NCS an asymmetric demyelinating sensory and motor neuropathy with focal slowing of the ulnar nerves at the elbow segment and temporal dispersion of the right fibular and tibial nerves at the leg segment.

In our patients, sensory CV slowing was a common feature, being more frequent in the ulnar, median, sural and radial SNAP. In addition, abnormalities in sensory CV were more frequent than those of motor $\mathrm{CV}$ outside the sites of compression as previously described ${ }^{3,12}$. It should be stated, however, that the SNAP usually are evaluated at the proximal regions due to technical difficulties, including physiological temporal dispersion and phase cancelation.

On motor conduction studies, DML was proportionately more affected than CMAP amplitudes and CV outside of sites of compression and also than F-wave latency, as previously described ${ }^{1,12,13}$. The most affected DML were those of the median, ulnar and deep fibular nerves, specially that of the median nerve, specially prone to pressure palsies and/or repetitive trauma ${ }^{12,13}$. On entrapment sites, almost half of the patients (19 patients, 48\%) referred some history of compression or precipitant factor prior the beginning of the 
symptoms, mainly in the fibular, ulnar and radial nerves, and less in the posterior tibial.

SNAP and CMAP amplitude reduction was not as frequent as CV abnormalities. Median and ulnar SNAP and deep fibular nerves CMAP were the most affected, as happened in other studies ${ }^{3,20,22}$.

Temporal dispersion was seen in sensory (median, ulnar and sural) and motor nerves (median, ulnar, posterior tibial and fibular) in segments susceptible to compression and also not susceptible segments. CB were observed in ulnar, fibular and radial nerves, being more frequent in the ulnar nerve at the elbow segment (7/57-12\%). The frequencies of CB described in previous studies vary greatly, from 6 to $22 \%^{28}$.
In summary our study showed that the classical clinical presentation of HNPP is the most frequent, but alternative presentations occur, including mononeuropathies, polyneuropathies and painful neuropathies. Pain should not exclude HNPP diagnosis. The electrophysiological features are much more homogeneous, characterized by a sensory and motor demyelinating multiple mononeuropathy with focal slowing of CV. The most frequent abnormalities on NCS were: prolonged DML of the median and ulnar nerves; CV slowing of ulnar motor nerve CMAP at the elbow segment; prolonged distal latency, reduced CV and prolonged minimal F-wave latency of the deep fibular nerve; reduced amplitude and CV of the median and ulnar SNAP; and reduced CV of the sural and superficial radial nerves.

\section{References}

1. Amato AA, Gronseth GS, Callerame KJ, Kagan-Hallet KS, Bryan WW, Barohn RJ. Tomaculous neuropathy: a clinical and electrophysiological study in patients with and without $1.5 \mathrm{Mb}$ deletions in chromosome 17p11.2. Muscle Nerve. 1996;19(1):16-22. doi:10.1002/(SICI)1097-4598(199601)19:1<16::AID-MUS3>3.0.CO;2-B

2. Mouton P, Tardieu S, Gouider R, Birouk N, Maisonobe T, Dubourg $O$ et al. Spectrum of clinical and eletrophysiologic features in HNPP patients with the 17 p11.2 deletion. Neurology. 1999;52(7):1440-6. doi:10.1212/WNL.52.7.1440

3. Infante J, Garcia A, Combarroso O, Mateio JI, Berciano J, Sedano $\mathrm{MJ}$ et al. Diagnostic strategy for familial and sporadic cases of neuropathy associated with 17p11.2 deletion. Muscle Nerve. 2001;24(9):1149-55. doi:10.1002/mus.1126

4. Chance PF, Alderson MK, Leppig KA, Lensch MW, Matsunami N, Smith $B$ et al. DNA deletion associated with hereditary neuropathy with liability to pressure palsies. Cell. 1993;72(1):143-51. doi:10.1016/0092-8674(93)90058-X

5. Li J, Parker B, Martyn C, Natarajan C, Guo J. The PMP-22 gene and its related diseases. Mol Neurobiol. 2013;47(2):673-98. doi:10.1007/s12035-012-8370-x

6. Lupski JR, Oca-Luna RM, Slaugenhaupt S, Pentao L, Guzzetta V, Trask BJ et al. DNA duplication associated with Charcot-Marie-Tooth disease type 1A. Cell. 1991;66(2):219-32. doi:10.1016/0092-8674(91)90613-4

7. Li J, Krajewski K, Lewis RA, Shy ME. Loss-of-function phenotype of hereditary neuropathy with liability to pressure palsies. Muscle Nerve. 2004;29(2):205-10. doi:10.1002/mus.10521

8. Lewis RA, Sumner AJ, Shy M. Electrophysiological features of inherited demyelinating neuropathies: reappraisal in the era of molecular diagnosis. Muscle Nerve. 2000;23(10):1472-87. doi:10.1002/1097-4598(200010)23:10<1472::AID-MUS3>3.0.CO;2-\#

9. Marques W Jr, Freitas MR, Nascimento OJM, Oliveira AB, Calia L, Melo A et al. 17p duplicated Charcot-Marie-Tooth $1 \mathrm{~A}$. Characteristics of a new population. J Neurol. 2005;252(8):972-9. doi:10.1007/s00415-005-0797-9

10. Uncini A, Guglielmo G, Muzio A, Gambi D, Sabatelli M, Mignogna $T$ et al. Differential electrophysiological features of neuropathies associated with 17p11.2 deletion and duplication. Muscle Nerve. 1995:18(6):628-35. doi:10.1002/mus.880180610

11. Pareyson D, Scaioli S, Taroni F, Botti S, Lorenzetti D, Solari $A$ et al. Phenotypic heterogeneity in hereditary neuropathy with liability to pressure palsies associated with chromosome 17p11.2-12 deletion. Neurology. 1996;46(4):1133-7. doi:10.1212/WNL.46.4.1133
12. Li J, Krajewski K, Shy ME, Lewis RA. Hereditary neuropathy with liability to pressure palsy. The electrophysiology fits the name. Neurology. 2002;58(12):1769-73. doi:10.1212/WNL.58.12.1769

13. Hong YH, Kim M, Kim HJ, Sung JJ, Kim SH, Lee KW. Clinical and electrophysiologic features of patients with 17p11.2 deletion. Acta Neurol Scand. 2003;108(5):352-8. doi:10.1034/j.1600-0404.2003.00132.x

14. Lenssen P. Hereditary neuropathy with liability to pressure palsy: phenotypic differences between patients with the common deletion and a PMP22 frame shift mutation. Brain. 1998;121(8):1451-8. doi:10.1093/brain/121.8.1451

15. Gouider R, LeGuern E, Gugenheim M, Tardieu S, Maisonobe T, Leger $\mathrm{JM}$ et al. Clinical, eletrophysiologic and molecular correlations in 13 families with hereditary neuropathy with liability to pressure palsies and a cromossome 17p11.2 deletion. Neurology. 1995;45(11):2018-23. doi:10.1212/WNL.45.11.2018

16. Dubourg O, Mouton P, Brice A, LeGuern E, Bouche P. Guidelines for diagnosis of hereditary neuropathy with liability to pressure palsies. Neuromuscular Disord. 2000;10(3):206-8. doi:10.1016/S0960-8966(99)00103-0

17. Nogués M, Barroso F, Rivero A, et al. Pain: unusual presentation of hereditary neuropathy with liability to pressure palsies (HNPP). Posters/Clin Neurophysiol. 2006;117:S121-336.

18. Yurrebaso I, Casado OL, Barcena J, Perez de Nanclares G, Aguirre $\cup$. Clinical, electrophysiological and magnetic resonance findings in a family with hereditary neuropathy with liability to pressure palsies caused by a novel PMP22 mutation. Neuromusc Disord. 2014;24(1):56-62. doi:10.1016/j.nmd.2013.09.005

19. Yilmaz U, Bird T, Carter G, Wang LH, Weiss MD. Pain in hereditary neuropathy with liability to pressure palsy: an association with fibromyalgia syndrome? Muscle Nerve. 2015;51(3):385-90. doi:10.1002/mus.24331

20. Verhagen WI, Gabreels-Festen AA, Wensen PJ, Joosten EM, Vingerhoets HM, Gabreëls FJ et al. Hereditary neuropathy with liability to pressure palsy: clinical, electroneurophysiological and morphological study. J Neurol Sciences. 1993;116(2):176-84. doi:10.1016/0022-510X(93)90323-Q

21. Cruz-Martinez A, Bort S, Arpa J, Duarte J, Palau F. Clinical, genetic and electrophysiologic correlation in hereditary neuropathy with liability to pressure palsies with involvement of PMP22 gene at chromosome 17p11.2. Eur J Neurol. 1997;4(3):274-86. doi:10.1111/j.1468-1331.1997.tb00347.x

22. Andersson PB, Yuen E, Parko K, So YT. Electrodiagnostic features of hereditary neuropathy with liability to pressure palsies. Neurology. 2000;54(1):40-4. doi:10.1212/WNL.54.1.40 
23. Luigetti M, Grande AD, Conte A, Lo Monaco M, Bisogni G, Romano A et al. Clinical, neurophysiological and pathological findings of HNPP patients with 17p12 deletion: a single-centre experience.J Neurol Sci. 2014;341(1-2):46-50. doi:10.1016/j.jns.2014.03.046

24. Merejota P, Silander K, Kalinmo H, Aula P, Meretoja A, Savontaus ML. Epidemiology of hereditary neuropathy with liability to pressure palsies (HNPP) in south western Finland. Neuromuscul Disord. 1997;(8):529-32. doi:10.1016/S0960-8966(97)00100-4

25. Lorenzoni PJ, Scola RH, Cardoso J, Kay CS, Fugmann EA, Marques W Jr et al. Swallowing dysfunction in hereditary neuropathy with liability to pressure palsies. Arq Neuropsiquiatr. 2008;66(4):898-900. doi:10.1590/S0004-282X2008000600027

26. Malamut RI, Marques W, Sumner AJ. Postsurgical Idiopathic Brachial Neuritis. Muscle Nerve. 1994;17(3):320-4. doi:10.1002/mus.880170310

27. Simmons Z. Electrodiagnosis of brachial plexopathies and proximal upper extremity neuropathies. Phys Med Rehabil Clin N Am 2013;24(1):13-32. doi:10.1016/j.pmr.2012.08.021

28. Sellmann MS, Mayer RF. Conduction block in hereditary neuropathy with liability to pressure palsies. Muscle Nerve. 1987;10(7):621-5. 